\title{
DOCUMENTOS EXISTENTES EM PORTUGAL SOBRE FERNÃO DE MAGALHÃES E AS SUAS VIAGENS
}

\author{
José Manuel Garcia \\ Academia Portuguesa da História / Academia de Marinha
}

Resumo: Neste trabalho procedemos ao inventário sistemático da documentação que se encontra em Portugal sobre Fernão de Magalhães e lhe é coeva, a qual está localizada na sua quase generalidade no Arquivo Nacional da Torre do Tombo. Para cada documento apontado são indicadas em nota de rodapé algumas das obras onde ele foi publicado. Neste levantamento apresentamos os testemunhos recolhidos por grupos temáticos e ordem cronológica, mostrando a importância que o conhecimento destas fontes tem para apurar com o maior rigor possível o que foram a vida e as viagens de Fernão de Magalhães.

Palavras-chave: Fernão de Magalhães; documentos da primeira circum-navegação; Descobrimentos portugueses; Porto.

Documents Existing In Portugal About Ferdinand Magellan and His Travels AвsтRAct: In this work we systematically inventory the documentation existing in Portugal about Ferdinand Magellan in his time, which is located almost in its entirety in the National Archive of Torre do Tombo. For each document discussed, there are footnotes indicating some of the works in which it was published. In this survey, we present the testimonies organised by thematic grouping and chronological order, demonstrating the importance of these documents as a means of exploring with the greatest possible rigor a clear understanding of the life and travels of Ferdinand Magellan.

Keywords: Ferdinand Magellan; first circumnavigation documents; Portuguese discoveries; Oporto.

Ao evocarmos Fernão de Magalhães nos quinhentos anos do início em I519 da mais audaciosa, difícil e longa viagem marítima da História dos Descobrimentos, a qual foi por ele dirigida, consideramos ser da maior oportunidade apresentar o conjunto dos testemunhos que nos ficaram em Portugal sobre este cavaleiro fidalgo da casa real portuguesa. Estamos perante textos que complementam de forma muito importante as valiosas narrativas que cronistas portugueses como João de Barros e Fernão Lopes de Castanheda nos deixaram sobre Fernão de Magalhães, as quais foram preparadas com base em fontes que em grande parte já desapareceram.

Garcia, José Manuel (2019). «Documentos existentes em Portugal sobre Fernão de Magalhães e as suas viagens». Abriu, 8, 15-33. ISSN: 2014-8526. e-ISSN: 2014-8534. DOI: 10.1344/abriuzorg.8.2. Received: $14 / 12 / 2018$. Accepted: $31 / 1 / 2019$. 
Ao procedermos aqui ao inventário sistemático da documentação coeva de Fernão de Magalhães que se lhe refere e conserva no seu país de origem verificamos quão necessário é o seu conhecimento para apurar com o maior rigor possível o que foi a sua vida e assim superar várias incorreções que sobre ela se têm cometido. ${ }^{\mathrm{I}}$

Relevamos ainda o facto de serem de destacar não apenas os testemunhos sobre a viagem levada a cabo por Fernão de Magalhães entre I5I9 e I521, mas também os que são relativos às viagens por ele já realizadas antes de a fazer, isto é, desde que em 1505 partiu de Lisboa para a Índia até aí regressar em 1513, depois de ter chegado a Malaca em I509 e às Molucas em I5I2, até que deixou Portugal a caminho de Espanha em outubro de 1517, onde ficou quase dois anos.

Organizámos este levantamento documental repartindo-o por núcleos temáticos e em cada um registando os dados nele contidos por ordem cronológica. ${ }^{2}$

Como a maior parte dos documentos referenciados se encontram em Lisboa no Arquivo Nacional da Torre do Tombo advertimos o leitor de tal facto não sendo por isso necessário estar a repetir tal informação. Limitamo-nos assim a registar as menções à Biblioteca Nacional de Portugal quando é necessário assinalar a localização dos testemunhos que não se encontram naquele arquivo.

Uma outra observação importante que também aqui deixamos é a de que indicamos de forma clara e acessível em nota de rodapé as obras onde os documentos inventariados podem ser lidos.

Por fim advertimos que nas conclusões elaborámos algumas apreciações muito sumárias com interpretações e análises sobre o valor e o significado das informações que tais fontes nos trazem para a história do grande navegador.

\section{Documentos Sobre Fernão de MAgalhães ANTES dA SUA PARTIDA PARA ESPANHA EM OUTUBRO DE 1517}

I) Março [?] de 1505, Lisboa - Registo do pagamento de iooo réis mais cevada como moradia atribuída a Fernão de Magalhães quando foi para a Índia ins-

r Parte deste trabalho fundamenta-se em investigações que apresentámos em Garcia (2007).

2 Não temos aqui em conta a grande quantidade de fontes que se prendem com as negociações que antecederam a assinatura do Tratado de Saragoça em I529, as quais se relacionaram com as consequências da viagem de Fernão de Magalhães, as quais em grande parte se encontram em Fonseca e Ruiz Asencio (1994). 
crito no «título dos moradores da casa del-rei nosso senhor, que este ano de I505 vão à Índia» [Biblioteca Nacional de Portugal, Pombalina cód. I23] (Silva (ig96: 304).

2) 27 de dezembro de I506, Cochim - Sumário de uma carta de D. Francisco de Almeida para D. Manuel, onde se refere Fernão de Magalhães. Por ter andado pouco e mal referenciada reproduzimos aqui a passagem que se lhe refere: «Os de Sofala que lá enviou: Nuno Vaz para capitam; e Duarte de Melo para capitão da caravela Espera; e António Raposo e Sancho Sanches para escrivães; Fernão de Magalhães, Luis Mendes de Vasconcelos e Pero da Fonseca, para andar por capitão do bergantim de Quíloa; Francisco de Anaia para arrecadar a fazenda de seu pai e se tornar» [Gaveta 20-4-15] (Albuquerque i884-1935: II, 395; Gavetas 1960-ı977: X, 359; Silva ı996: 329).

3) 30 de julho de 1509 , Cochim - Registo de que Fernão de Magalhães recebeu do almoxarife desta cidade 20 paras de trigo, à conta dos seus soldos num "Caderno das pessoas que tomaram trigo, arroz, e outras couzas de seus soldos em Cochim desde 10 de maio de 1509 até abril de 1512» [Contos do Reino e Casa, Núcleo Antigo 595, fl. 6 (cota antiga: Listas da gente de guerra, maço I. ${ }^{\circ}$, n. ${ }^{\circ}$ 5)] (Baião igo5: III, 306).

4) 6 de setembro de i5ı, Cananor - Primeiro mandado de Afonso de Albuquerque para fornecer armamento a Fernão de Magalhães [Corpo Cronológico II-23-I04] (Albuquerque I884-I935: I, 287-288; Garcia 2007: 22).

5) 7 de setembro de 1510 , Cananor - Segundo mandado de Afonso de Albuquerque para fornecer armamento a Fernão de Magalhães [Corpo Cronológico II-23-I06] (Albuquerque I884-I935: I, 288-289; Garcia 2007: 22).

6) 2 outubro de I5Io, Cochim / 5 de junho de I5I6, Lisboa - Instrumento e carta de sentença de D. Manuel sobre o pagamento de uma dívida de $200 \mathrm{cru}-$ zados a Fernão de Magalhães [Corpo Cronológico, II-65-ı)] (Baião ı905: 309-310; Garcia 2007: 31-34).

7) I2 de outubro de I5ı, Cochim - Parecer dado por Fernão de Magalhães a Afonso de Albuquerque [Corpo cronológico II-23-190] (Albuquerque I884I93: II, 7; Garcia 2007: 23).

8) 29 de março de 15ı4, Azamor - Petição feita por Fernão de Magalhães a D. Manuel para que se lhe pagasse o resto do valor do cavalo que lhe foi morto a I de setembro de I5I3 nessa cidade [Corpo Cronológico, II-45-2I8] (Denucé I9II: I30-I3I e parcialmente por Lagoa I938: I, I49; Garcia 2007: 27-28). 9) 4 de setembro de 15I4, Lisboa - Mandado de D. Manuel para que se pague em Ponte de Lima a dívida de 200 cruzados a Fernão de Magalhães depois 
de este regressar de Azamor [Corpo cronológico, I-I6-3] Viterbo i988: parte I, I97-I98; Garcia 2007: 34-35.

ı) I5I4 - Indicação de que Fernão de Magalhães, filho de Rui de Magalhães, serviu dez meses em Azamor [Gaspar Álvares Lousada, Sumários da Torre do Tombo, tomo $3 \cdot{ }^{\circ}$ f. 366 v. na Biblioteca Nacional de Portugal] (Baião 1905: 312).

II) I5I4 - Pagamento de alimentos a Fernão de Magalhães em Azamor estando com o seu irmão Duarte de Sousa entre a gente de guerra de Aires Teles em «Pagamentos efetuados à gente da ordenança que serviu a cavalo na cidade de Azamor no ano de I5I4" [Contos do Reino e Casa, Núcleo Antigo 606, fl. i6 (cota antiga: Listas de gente de guerra, maço $4 .{ }^{\circ}$, n. ${ }^{\circ}$ 2)] (Baião I905: 306).

12) 4 de julho de 1515, Lisboa / 24 de novembro de 1516, Ponte de Lima - Instrumento de procuração passado por Fernão de Magalhães a seu irmão Duarte de Sousa para que recebesse o montante da dívida que lhe iria ser paga em Ponte de Lima e recibo do pagamento desse montante [Corpo cronológico, II-58-179] (Baião I905: 31I; Garcia 2007: 35-37).

13) 1515, Lisboa - Registo de duas verbas indicadas no Livro de receitas e despeza de Heytor Nunes, tesoureiro da Casa da India, relativo ao ano de 1515, f. 47: «Pagos a Fernão de Magalhães 43435 réis, em comprimento de 69343 réis, que lhe monta pelos 20 quintais 2 arrobas de suas quintaladas»e f. 58 : «Pagou a Fernão de Magalhães I36 24I réis, que lhe monta pelos 39000 réis que lhe vieram nesta nau ao partido do meio» [Contos do Reino e Casa, Núcleo Antigo 809]. (Viterbo I988: parte II, 227). ${ }^{3}$

I4) I5 de abril de 1516, Santarém - Registo do pagamento de uma moradia a Fernão de Magalhães no valor de i 250 reais por mês [Gaspar Álvares Lousada, Sumários da Torre do Tombo, tomo $3 .^{\circ}$ f. 366 v. na Biblioteca Nacional de Portugal] (Baião I905: 312).

15) ig de maio de 1517, Lisboa - Conhecimento de Fernão de Magalhães declarando ter recebido a maior parte da dívida que João Abraldez tinha para com ele [Corpo cronológico in-68-I24]. ${ }^{4}$

3 Nesta publicação o autor refere-se vagamente à localização destes documentos como estando «no livro de Henriques Nunes», mas pela referência apressada que lhe é feita corresponde a um lapso ou gralha para se referir ao livro que acima citamos e ele referira pouco antes, na p. 200, dando-lhe então a cota antiga de: «Armário 20 do Interior da Casa da Coroa».

4 Documento que descobrimos e publicámos pela primeira vez em Garcia (2007: 37). 


\section{DOCUMENTOS ESPANHÓIS RELATIVOS À PREPARAÇÃO DA VIAGEM DE FERNÃO DE MAGALHÃES}

I) 22 de março de 15ı8, Valhadolide - Capitulações de Carlos V com Fernão de Magalhães e Rui Faleiro sobre a viagem às Molucas então determinada, as quais foram aqui registadas num traslado do original feito a i4 de maio de 1518 em Sevilha [Gaveta I8-ı-4] (Gavetas I960-1977: IX, 516-528).

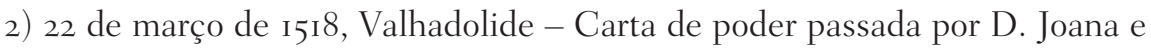
Carlos V nomeando Rui Faleiro e Fernão de Magalhães, capitães de uma armada que ia a descobrir [Gaveta I8-8-39] (Academia das Ciências de Lisboa I892: 418-419; Gavetas (I960-1977: IX, 404-406).

3) 28 de fevereiro de 1519 , Barcelona - Carta de Carlos V a D. Manuel I [Gaveta I8-5-26] (Gavetas I960-1977: IX. 422-423; Cortesão I956-I96ı: I, 38-39; Gavetas 1960-I977: VIII, 554; Garcia 2007: 156-157).

4) 6 de abril de 1519, Barcelona - Regimento dado a Juan de Cartagena em que se incluem capítulos do regimento de Fernão de Magalhães e Rui Faleiro [Corpo cronológico iı-7-18] (Academia das Ciências de Lisboa (1892: 423-430).

5) I9 de abril de I519, Barcelona - Carta de Carlos V a Fernão de Magalhães, Rui Faleiro e às pessoas que iam na armada que mandava às Molucas [Corpo cronológico I-24-64] (Academia das Ciências de Lisboa ı892: 430).

\section{CORRESPONDÊNCIA SOBRE FERNÃo de MAGALHÃES ENVIADA}

\section{A D. MANUEL I ANTES DA PARTIDA PARA A SUA VIAGEM EM 1519}

I) 28 de setembro de 1518, Saragoça - Carta de Álvaro da Costa referindo as diligências que fizera junto de Carlos V para que a expedição às Molucas não se realizasse [Gaveta I8-8-38] (Cortesão I956-ı96ı: I, 35-37; Gavetas I960I977: IX, 403-404; Garcia 2007: I54-156).

2) Io de maio de I519, Barcelona - Carta de João Rodrigues onde refere ter falado a Fernão de Magalhães sobre a viagem que este planeava realizar. Este documento foi escrito depois de Carlos V ter enviado a D. Manuel a carta datada de Barcelona a 28 de fevereiro de I519, já atrás referida [Corpo cronológico I-I0-3I] (Cortesão I956-I96r: I, 40-4I; Garcia 2007: 157-158).

3) I8 de julho de 1519, Sevilha - Carta de Sebastião Álvares sobre o seu encontro com Fernão de Magalhães [Corpo cronológico I-13-20] (Academia das Ciências de Lisboa I892: 431-435; Cortesão 1956-I96I: I, 42-50; Garcia 2007: 158-163). 


\section{CORRESPONDÊNCIA DE PORTUGUESES PARA D. MANUEL I \\ E D. JoÃo III SOBRE FERNÃo dE MAGALHÃES, DEPOIS DE ESTE TER PARTIDO PARA A SUA VIAGEM EM 1519}

I) 23 de agosto de 1520, Malaca - Carta de Garcia de Sá indicando a suspeita de haver três naus de Fernão de Magalhães no Índico [Gaveta I5-I0-2] (Sá I954-I988: I, II6-II7; Gavetas 1960-I977: IV, 245-246; Garcia 2007:I09 parcialmente).

2) 28 de abril de I522, Banda - Carta de António de Brito com notícias sobre os castelhanos que estavam nas Molucas, incorporada na carta de Jorge de Albuquerque escrita em Malaca a 28 de agosto de 1522 [Corpo cronológico III-15-8I] (Sá I954-I988: I, I28-I30; Garcia 2007: I67-168).

3) I I de fevereiro de 1523 , Ternate - Primeira versão de uma carta escrita em Ternate por António de Brito sobre a viagem de Fernão de Magalhães [Gaveta ı8-6-9] (Sá 1954-ı988: I, I32-ı58; Gavetas ı960-1977: VIII, 632-645; Garcia 2007: 168-183).

4) I5 de fevereiro de 1523 , Ternate - Carta de Rui Gago com notícias sobre Fernão de Magalhães e as Molucas [Gaveta ı8- 6-6] (Sá I954-I988: I, I59-ı74; Gavetas ig60-I977: VIII, 603-6iI).

5) 6 de maio de I523, Ternate - Segunda versão com aditamentos da carta escrita em Ternate em i I de fevereiro por António de Brito [Gaveta I8-2-25] (Academia das Ciências de Lisboa I892: 464-474; Gavetas I960-I977: VIII, 20I-215; Garcia 2007: I68-I83).

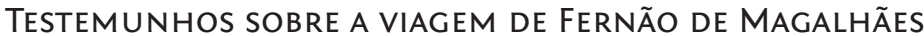

I) I de junho de 1522, Malaca - Depoimento de Martin de Aiamonte sobre a viagem de Fernão de Magalhães que terá seguido em 28 de agosto de 1522 com cartas então enviadas por Jorge de Albuquerque para Portugal [Corpo cronológico Iı-I0I-87] (Baião I932: 276-28I; Águas 1987: ı87-ı97; Garcia 2007: I84-189).

2) Relação da «Navegação e viagem que fez Fernando de Magalhães de Sevilha pera Maluco no ano de I5I9 anos», por um piloto genovês que era León Pancaldo. Este texto corresponde à tradução feita na Índia de um original perdido, tendo sido trazido para Portugal por D. Duarte de Me- 
neses, quando de lá partiu a 20 de janeiro de 1525 [Ms. Brasil 25, f. I63I73]. ${ }^{5}$

3) 25 de outubro de 1525 , ilha de Moçambique - Carta de Baptista Aponcoso e León Pancaldo a Carlos V sobre a viagem que haviam feito com Fernão de Magalhães [Gaveta I7-6-24] (Sá I954-ı988: I, I97-20I; Gavetas 1960-ı977: VII, 38I-384).

\section{Sobre a Vinda de Malaca para lisboa de Fernão de MaGalhãeS eM 1513}

Para lá da apresentação do conjunto da documentação relativa a Fernão de Magalhães atrás referida, consideramos oportuno tecer algumas considerações esclarecedoras sobre o que se sabe da viagem em que ele veio de Malaca para Lisboa em I513. Nesse sentido vamos analisar testemunhos existentes no Arquivo Nacional da Torre do Tombo, conjugados com fontes cronísticas. Este tema é importante para a sua biografia pois permite contrariar a afirmação feita em várias publicações de que Fernão de Magalhães não poderia ter ido às Molucas em I512 por nesse ano já estar em Lisboa. Tal estadia em Lisboa nessa altura é impossível, não apenas porque se baseia em referências feitas a um seu homónimo, filho de um Pedro de Magalhães (Baião I905: III, 305), mas porque também não tem em conta o facto de pessoas que participaram na conquista de Malaca, e as notícias da sua conquista, só terem chegado a Lisboa em I513 (Garcia 2017: 438). Ora, Fernão de Magalhães embarcou em Malaca numa armada de três navios que daí partiu a in de janeiro de I513 e chegou a Cochim a 10 de fevereiro de 1513, de onde seguiu para Lisboa num desses navios que se chamava Santa Cruz. ${ }^{6}$ Pouco tempo depois de Fernão de Magalhães ter regressado à capital portuguesa incorporou-se a 17 de agosto de 1513 na expedição que então dali seguiu para a conquista de Azamor.

5 Este texto foi publicado pela primeira vez no ano 1826 pelo Cardeal Saraiva na Collecção de noticias para a História e Geografia das nações ultramarinas, que vivem nos dominios portuguezes, ou thes são visinhas (Lisboa, Academia Real das Ciências), tendo aí a indicação «II. Roteiro da viagem de Fernão de Magalhães, escrito por um piloto genovês que o acompanhou», tendo depois outras edições nomeadamente em Águas (1987: I47-I63) e Garcia (2007: 210-223).

${ }^{6}$ Cf. as criteriosas observações sobre esta conjuntura assinaladas por Veloso (1941: 23-24). 
Esta vinda de Fernão de Magalhães no referido navio Santa Cruz está bem atestada na acima citada carta de sentença de D. Manuel passada em Lisboa a 5 de junho de 1516 pois nela se afirma de forma bem elucidativa que:

[...] tornando ele autor [Fernão de Magalhães] como de feito tornara a risco da nau Santa Cruz, de que era capitão Jorge Lopes, a qual nau em que ele autor tornara sobre si, a risco, o qual viera a salvamento a estes reinos de Portugal com toda sua carga. (Garcia 2007: 32)

Sobre o navio Santa Cruz aqui em causa podemos precisar algumas informações de acordo com as fontes conhecidas, começando por indicar que ele foi um dos quatro que integrava a armada financiada por mercadores que em ı5ı0 D. Manuel enviou a Malaca sob a direção de Diogo Mendes de Vasconcelos.

Afonso de Albuquerque alterou os comandos dos navios dessa armada depois de Diogo Mendes de Vasconcelos se ter revoltado em Goa em i5io contra a sua autoridade, por querer ir a Malaca sem o seu consentimento. Tal facto pode ler-se numa carta de Afonso de Albuquerque de i de abril de I512 do Corpo Cronológico I-II-50, onde escreveu que: «quando os prendi (aos capitães desses navios), dei as capitanias das naus, a Fernão Peres a Trindade, e a Gaspar de Paiva Santo António, e a Dom João a Conceição e a caravela a James Teixeira» (Albuquerque ı884-1935: I, 60). Este último navio, que então foi denominado caravela, era a Santa Cruz, sendo de novo mencionado por Afonso de Albuquerque na carta do Corpo Cronológico I-22-62 que está datada de 20 de agosto de I5I2, nela registando que ao deixar Malaca a 20 de janeiro de I5I2: «as duas (naus) dos mercadores e a caravela ficaram aguardando por carga com dinheiro e mercadorias suas» (Albuquerque I884-I935: I, I68), tendo a outra nau, que era a Trindade, vindo com ele de Malaca para Cochim.

A referida Santa Cruz foi mencionada por Fernão Peres de Andrade numa carta a Afonso de Albuquerque que se encontra no Corpo cronológico i II-5-10 e está datada de Cochim a 22 de fevereiro de 1513. Nela se pode ler: «Nossa partida de Malaca foi a onze de janeiro [de 1513] com a nau Anunciada, e Santo António, e Santa Cruz; a rezão por que partimos tão tarde verá vossa senhoria lá diante; acheguei a Cochim a dez de fevereiro» (Albuquerque I884-I935: III, 5I).

João de Barros elucidou que nestes navios ia António de Abreu, que tinha vindo do descobrimento das Molucas: 
Fernão Peres, como estava meio carregado pera se partir pera a Índia (segundo dissemos), em poucos dias se tornou a perceber de todo, e entregue a capitania-mor do mar a João Lopes de Alvim, a quem Afonso de Albuquerque proveu dela, partiu de Malaca com três velas carregadas de especiaria, ele em uma, e nas duas Lopo de Azevedo e António de Abreu, que vinha de descobrir Maluco. (Barros I553: livro 9, capítulo 5)

Fernão Lopes de Castanheda também se reportou a António de Abreu e aos referidos navios da seguinte forma:

E porque a fortaleza [de Malaca] ficava segura, e se acabava o ano que Fernão Peres prometera ao governador de ficar em Malaca, e por estar descontente de Rui de Brito, partiu-se pera a Índia no mês de janeiro de mil e quinhentos e treze, e foram com ele Lopo de Azevedo no seu navio [A Anunciada] e António de Abreu em Santo António, e na sua nau [a Santa Cruz] foi com ele Vasco Fernandes Coutinho por ser desfeito o seu navio. (Castanheda I552: capítulo I02)

Das menções aqui feitas ao navio Santa Cruz, referenciado de várias formas, o que na altura era vulgar, deduz-se que foi o único com esse nome a ter ido a Malaca em I5I I e a regressar a Lisboa em I5I3, como o atestou o acima referido documento de D. Manuel ao registar que nele viera embarcado Fernão de Magalhães. Este facto contribui fortemente para reforçar o facto de o famoso navegador ter ido com António de Abreu às Molucas, ida que foi apontada em referências bem explícitas feitas de forma assertiva por autores seguros e coevos de Fernão de Magalhães como foram Gonzalo Fernández de Oviedo y Valdés, Fernão Lopes de Castanheda e Fernando Oliveira, não havendo qualquer menção a negá-la.7 Esta situação permite-nos afirmar que quando Fernão de Magalhães chegou às Filipinas a I6 de março de I52 I ele concluíra de forma indireta a primeira circum-navegação do globo, pois nove anos antes havia feito a primeira parte dessa volta ao chegar a longitudes idênticas que correspondem àquelas onde se situam as Molucas. ${ }^{8}$

7 Sobre este assunto além do que já referimos em Garcia (2007) e mais recentemente em Garcia (2019).

${ }^{8}$ Esta noção que defendemos e temos divulgado já foi avançada anteriormente por vários autores de entre os quais nos limitamos a citar a título de exemplo os seguintes: Veloso (1941: 95-96) («pode legitimamente afirmar-se que o grande navegador deu a volta ao mun- 


\section{Do ENVIO DA PRIMEIRA CARTA DE FRANCISCO SERRÃo A FERNÃO DE MAGALHÃES EM 1514 E DA SUA RESPOSTA EM 1516}

Um outro assunto importante da biografia de Fernão de Magalhães é esclarecido numa carta datada de Malaca a 8 de janeiro de I5I5 que Jorge de Albuquerque, então capitão daquela cidade, enviou a D. Manuel e está atualmente no Corpo cronológico in i-5-87. Nela se declara que:

Veio António de Miranda de Banda, onde o tinha mandado Rui de Brito. Veio a falar em Ambon com Martim Guedes, Francisco Serrão, que se perdeu quando foram a descobrir Banda; está em Maluco nas ilhas do cravo.

Todos aqueles reis daquelas ilhas querem ser vassalos de vossa alteza, e todos desejam que se façam fortalezas vossas, nas suas terras, e todos escrevem a vossa alteza em malaio. Eu as mandei trasladar aqui de malaio em português, e os mando com os traslados, e assim outra carta dos honrados de Ambom, e as cartas de Francisco Serrão. (Albuqerque i884-I915: III, I33-139; Sá 1954-I988: I, 79-80)

Este documento é essencial para esclarecer e corrigir plenamente um assunto que tem sido expresso muitas vezes com erros desde o século xvi. Com efeito nele se evidencia que foi apenas em I5I4 que se soube estar Francisco Serrão não apenas vivo, mas a prosperar em Ternate, nas Molucas do Norte. Como se vê pelo texto citado, foi no referido contexto que ele enviou de Ambon, nas Molucas do Sul, as suas cartas a autoridades portuguesas e a outras pessoas, de entre as quais se contava o seu grande amigo Fernão de Magalhães, com o qual fora para a Índia em 1505 e por quem havia sido salvo em Malaca em I509, quando ambos lá foram pela primeira vez. Nesse texto aquele fidalgo aventureiro incentivou Fernão de Magalhães a ir ter com ele a Ternate, facto que teve grande importância para a génese do projeto que este último alimentou de querer voltar às Molucas, tendo-lhe tal documento servido para o apoiar como prova do interesse que nutria pelas ilhas.

Fernão de Magalhães só pode ter recebido em Lisboa essa carta em meados de 1515, pois ela seguiu num dos navios da carreira da Índia que então aí

do») e Eliot Morison (I974: 317) («The fact that Magellan sailed with Abreu as far as Ambon and Banda justifies us in naming him as the first person of any race to circumnavigate the globe»). 
chegou. Ele, por sua vez, só podia ter respondido ao seu amigo no ano seguinte numa carta que seguiu em navio que foi para a Índia em I516, o qual admitimos poder ter sido o que foi referenciado por João de Barros da seguinte forma:

[...] uma nau deste reino, capitão e mestre um Diogo de Unhos, homem diligente nas cousas do mar, o qual partira deste reino a vinte quatro de abril do ano de quinhentos e dezasseis, depois de ser partida a armada que aquele ano el-rei despachou pera a Índia. E teve tanta diligência e dita em sua navegação, que chegou primeiro um mês que as naus que partiram ante dele. (Barros 1563: Livro I, cap. 2)

Teria sido assim a 24 de abril de 1516 que seguiu a carta de Fernão de Magalhães para Francisco Serrão na qual lhe dizia, pouco depois de ter voltado de Azamor e quando já se começara a agravar de D. Manuel, que ele o esperasse lá, pois iria às Molucas por via portuguesa ou, caso não o pudesse fazer, por uma via castelhana. Esta atitude revelava não estar ainda completamente fechada a via oriental portuguesa, o que só viria a acontecer em I517, quando lhe foi recusado o aumento da moradia em ıoo réis e a possibilidade de ir às Molucas. Ainda assim tal ida já estava em causa em abril de 15ı16, daí que equacionasse uma via alternativa ocidental para ir ter com ele, facto que o levou a deixar Lisboa e a partir para Sevilha, onde chegou a 20 de outubro de 1517.

Desta forma podem-se precisar as preciosas referências que João de Barros fez à génese do projeto de Fernão de Magalhães e à correspondência que trocou com o seu amigo ao escrever o seguinte:

Atrás escrevemos como Francisco Serrão, das Ilhas de Maluco onde foi ter, escreveu algumas cartas a Fernão de Magalhães, por ser seu amigo do tempo que ambos andaram na Índia, principalmente na tomada de Malaca, dando-lhe conta das ilhas daquele Oriente. Ampliando isto com tantas palavras e mistérios, fazendo tanta distância donde estava a Malaca, por fazer em si pera méritos de seu galardão ante el-Rei D. Manuel, que parecia virem aquelas cartas de mais longe que dos antípodas, e de outro Novo Mundo, em que tinha feito mais serviço a el-Rei, do que fizera o Almirante D. Vasco da Gama no descobrimento da Índia. As quais cartas foram vistas na mão de Fernão de Magalhães, porque se prezava ele muito da amizade de Francisco Serrão, e em as mostrar denunciava aquele grande serviço que tinha feito a el-Rei; e também ele estribou logo tanto nelas pera o propó- 
sito que delas concebeu, que não falava em outra cousa. O qual propósito se viu depois em cartas suas, que se acharam entre alguns papéis que ficaram per falecimento de Francisco Serrão, lá em Maluco, que António de Brito mandou recolher, e eram repostas das que lhe ele, Francisco Serrão, escrevia (como ora veremos), nas quais dizia que, prazendo a Deus, cedo se veria com ele; e que, quando não fosse per via de Portugal, seria per via de Castela, porque em tal estado andavam suas cousas; portanto que o esperasse lá, porque já se conheciam da pousada pera ele esperar que ambos se haveriam bem. (Barros 1563: Livro V, cap. 8)

De forma complementar a estas informações de João de Barros é igualmente muito elucidativo para compreender o tempo em que se verificou a génese do projeto de Fernão de Magalhães, que o iria imortalizar, um outro documento que se encontra na Gaveta I3-6-i que corresponde a uma inquirição feita a 25 de agosto de I523, em Tomar, a várias personalidades sobre o «descobrimento de Maluco». Nele se indica que Fernão de Magalhães, entre o seu regresso do Oriente, em I5I3, e meados de I5I6, manteve uma atitude que não denunciava o comportamento que de seguida iria ter. Tal realidade foi afirmada com toda a clareza no importante depoimento ali prestado por Rui de Brito Patalim. Este fidalgo fora com Afonso de Albuquerque para Malaca em i5i i e, entre 20 de janeiro de I5I2 e inícios de junho de I5I4, foi o seu primeiro capitão, aí tendo conhecido Fernão de Magalhães. No referido depoimento, declarou que, após ter regressado a Portugal: «achou ainda Fernão de Magalhães na corte e neste reino pacífico e bem fora de se ir dele, e que estaria depois da vinda dele testemunha ainda um ano, ou pouco menos, ficando já o trato de Maluco assentado e pacífico como dito é» (Gavetas ig60-I977: III, 36). Rui de Brito Patalim deixara Malaca em finais de I5I4 e partiu da Índia em inícios de I5I5, tendo atracado em Lisboa em meados desse mesmo ano, certamente na altura em que chegaram também à capital portuguesa as cartas com as notícias de que Francisco Serrão estava em Ternate, entre as quais se encontrava a que era dirigida a Fernão de Magalhães. De acordo com aquela declaração verifica-se que Fernão de Magalhães «estaria depois da vinda dele testemunha ainda um ano ou pouco menos», pelo que só por volta de abril de i5i6, isto é, após o seu regresso de Azamor, ele teria começado a adotar atitudes menos «pacíficas», isto é, a preparar o seu projeto afrontoso para D. Manuel, com a ida às Molucas por ocidente, visto não ter sido aumentada a sua moradia, que então acabara de receber. 


\section{Sobre a naturalidade de Fernão de Magalhães}

Para terminar as indicações documentais que aqui formulamos sobre Fernão de Magalhães existentes em Portugal, é ainda muito importante chamar a atenção para uma fonte fundamental sobre a sua naturalidade que descobrimos recentemente e mais à frente apontamos. Ela vem reforçar o facto já por ele próprio expresso de que era «vizinho da cidade do Porto», o que seguindo a legislação da época queria dizer que era natural daquela cidade. Com efeito sabe-se desde i837, por uma "pública escriptura de obligación» datada de 23 de fevereiro de I51 8 e assinada em Valhadolide por Fernão de Magalhães, Rui Faleiro e Juan de Aranda, que ele se identificava oficialmente como sendo «vecino de la ciudad del Puerto» (Fernández de Navarrete I925-1837: 4, I10).

A naturalidade portuense de Fernão de Magalhães foi igualmente apontada pelo humanista e polígrafo Fernando de Oliveira numa obra que intitulou Viagem de Magalhães na demanda de Maluco por el-rei de Castela, o qual poderia ter sido escrito originalmente cerca de 1536 e se encontra atualmente na biblioteca da Universidade de Leiden.

Temos chamado a atenção para esta fonte portuguesa por ser particularmente relevante para o esclarecimento de aspetos fundamentais da biografia de Fernão de Magalhães, não apenas para o que é relativo à sua naturalidade, mas também à circunstância de ele ter sido um dos descobridores das Molucas em I5I2. Tais factos podem ler-se na seguinte passagem:

Antre os portugueses que descobriram Maluco foi um chamado Fernão de Magalhães, natural da cidade do Porto, em Portugal. Este era da geração dos Magalhães, gente honrada e nobre, e era criado del-rei em foro de moço da câmara, e homem entendido na arte da navegação e cosmografia, em especial pelo que aprendeu de um seu parente chamado Gonçalo de Oliveira, em cuja companhia foi ter aquela terra, do qual entendeu a verdade do sítio daquelas terras, porque era Gonçalo de Oliveira mui sabido nesta faculdade. (Garcia 2007: 197)

Alinhando com o que Fernando de Oliveira escreveu com toda a firmeza sobre a naturalidade portuense de Fernão de Magalhães, temos a informação a que acima aludimos e encontrámos numa afirmação feita em I549 pelo «cidadão do Porto» que era o doutor João de Barros, quando tinham decorrido escassos vinte e oito anos da morte de Fernão de Magalhães. Nessa informação escrita por aquele homónimo do justamente famoso cronista, refere-se 
que do Porto «foi natural o Magalhães». Esta frase formulada de uma forma tão peremptória surge num manuscrito do Libro das antiguidades e cousas notaneis de antre Douro e Minho, e de outras m[ui]tas de España e Portugal. Por Ioão de barros. Composto no an [n]o de I549, que se encontra inédito na Biblioteca Nacional de Portugal, com a cota Cod 2i6. No seu f. 50, Fernão de Magalhães é destacado a propósito do elogio feito aos homens do Porto tidos por «muito espertos na arte do mar», o que é exemplificado pela afirmação que: «dali foi natural o Magalhães, que achou outro caminho para a Índia, que foi homem habilíssimo». Esta indicação manifesta em toda a sua eloquência uma afirmação que, quanto a nós, acaba de vez com as dúvidas que foram apresentadas sobre a naturalidade de Fernão de Magalhães. Com efeito a atribuição muito divulgada de que ele teria nascido em Sabrosa resulta de uma falsificação documental elaborada em I796 a qual já está desde há muito tempo devidamente esclarecida. ${ }^{9}$ Quanto à hipótese de ele poder ter nascido em Ponte da Barca não há qualquer registo documental que a sustente, pois nessa região apenas se sabe que ele teve antepassados e familiares.

O texto acima citado do doutor João de Barros é tão claro como explícito e rigoroso no evidenciar o registo seguro de que Fernão de Magalhães era do Porto, facto que não lhe suscitou qualquer dúvida ou hesitação, tal como não a suscitara a Fernando Oliveira, sendo que ambos os autores além de serem coevos do navegador, são dignos de toda a credibilidade e tinham em conta a circunstância de tal personalidade ser então bem conhecida no Porto. Daí que ele tenha sido referido, pelo doutor João de Barros, em termos elogiosos, ao dizer «que foi homem habilíssimo», e exemplo dos homens dessa cidade que se notabilizaram na «arte do mar», sem que revelasse qualquer sensação de hostilidade face à acusação de traição, de que ele foi alvo da parte de outros autores que publicaram as suas obras depois de ele ter escrito a sua.

De assinalar ainda que a referência à obra do doutor João de Barros acima citada para registar a indicação de que Fernão de Magalhães nasceu no Porto, surgiu num texto datado de janeiro de i62 I, escrito pelo justamente famoso e conceituado erudito Manuel Severim de Faria num códice com a indicação de ser o «Décimo oitavo tomo das obras do senhor Manuel Severim de Faria, chantre e cónego de Évora», que se encontra no Arquivo Nacional da Torre do Tom-

9 Cf. a título de exemplo Lagoa (I938: I, 88-97); Veloso (I941: I2-I4); Castro; Hamon e Thomaz. (2010: 312-314); Barros (2015: 36-46). 
bo - Casa de Cadaval, n. ${ }^{\circ}$. Neste interessante livro inédito reúnem-se quarenta e duas biografias, sendo, no seu f. 79 que Manuel Severim de Faria, ao começar a tratar de «Fernão de Magalhães», afirmou ser o Porto a cidade de onde é natural: «nasceu Fernão de Magalhães na cidade do Porto».

Este autor acrescentou ainda a referência correta de que Fernão de Magalhães era «filho de Rui de Magalhães, alcaide-mor de Aveiro, e de Aldonça de Mesquita», sendo que estes últimos dados não foram registados pelo doutor João de Barros, revelando assim quão bem informado estava Manuel Severim de Faria sobre o navegador.

\section{CONCLUSÕES}

Da apreciação do conteúdo dos documentos antigos existentes em Portugal relativos a Fernão de Magalhães verificamos que os mais remotos são relativos à sua vida antes da sua partida para Espanha em outubro de 1517, neles se refletindo quer a sua experiência no Oriente, que foi decisiva para a idealização e concretização do seu projeto de querer ir às Molucas por uma via ocidental, quer a sua situação em Portugal e Marrocos, em particular sobre questões relativas aos seus rendimentos e moradia. ${ }^{10}$ É assim que sabemos que em 1505 , quando ele foi para a Índia, auferia como cavaleiro fidalgo uma moradia mensal no valor de 1000 réis mais cevada e que em 1516, nas vésperas de abandonar Portugal, a moradia que então lhe foi paga ascendia a 1250 réis, «com alqueire de cevada por dia dos derradeiros 6 meses do ano passado de $\left.{ }^{\left[{ }_{15}\right.}\right]_{15}$ e dos primeiros 3 deste que serviu em Azamor». Esta indicação permite estabelecer que, além do valor dessa moradia, Fernão de Magalhães esteve em Azamor entre julho de 1515 e março de 1516, aí tendo regressado para provar a sua inocência de um delito que ali não cometera, tendo trazido a prova da sua inocência. Tal facto não demoveu D. Manuel I da sua má vontade contra ele e por isso não lhe ter aumentado a sua moradia em ıoo réis, como ele queria, sendo tal circunstância um dos principais motivos para ele ficar agravado com o monarca. Caso tal aumento lhe tivesse sido pago, Fernão de Magalhães não teria alcan-

10 A moradia era uma espécie de ordenado ou tença paga em dinheiro e cevada a fidalgos da Casa Real que estivessem ao serviço do rei, a qual era registada em livros próprios para esse fim e variava segundo a condição de cada um. 
çado a notabilidade que conquistou, porque entre 1516 e 1517 idealizou um projeto de ir às Molucas por ocidente ao serviço de Castela, já que o rei português também não o autoriza a ir a essas ilhas por oriente, como se deduz de uma indicação de João de Barros já atrás citada.

Da restante documentação aqui apresentada verificámos ainda que ela testemunha o tipo de pagamentos de alimentos que lhe foram feitos enquanto esteve ao serviço do Estado da Índia, quer sob a alçada do seu primeiro vice-rei D. Francisco de Almeida, que o mandou para Quíloa em 1506, quer em Cananor, onde esteve depois de ter participado na batalha naval de Diu em I509, quer ainda ao seu armamento que lhe foi concedido em i5io pelo governador Afonso de Albuquerque, com quem participou nas conquistas de Goa, em I510, e Malaca, em i5ı. Particularmente elucidativo é o seu parecer negativo dado a Afonso de Albuquerque no conselho que este reuniu em Cochim sobre certos navios não deverem ir à conquista de Goa por a sua partida de regresso a Portugal poder estar comprometida por razões náuticas.

Através desses documentos sabemos ainda o tipo de negócios em que Fernão de Magalhães estava envolvido na Índia, os quais passavam nomeadamente pelo empréstimo de 100 cruzados a Pedro Anes Abraldez, quantia que lhe devia ser restituída no dobro desse valor em Portugal. Vários documentos atestam quão difícil foi Fernão de Magalhães reaver tal quantia até à sua partida para Castela em i5ı7.

A documentação conhecida também atesta as atividades de Fernão de Magalhães em Azamor, onde lhe mataram um cavalo quando participava nas operações iniciais da conquista dessa cidade em I513. Por a indemnização integral de tal perda não lhe ter sido dada, ele protestou exigindo o pagamento do resto do valor que se lhe ficara a dever.

A documentação aqui apresentada também esclarece que o Fernão de Magalhães que esteve em Azamor em I5I4 era filho de Rui de Magalhães não sendo assim um seu homónimo coevo cujo pai era Pero de Magalhães, assunto que suscitou algumas confusões e levaram nomeadamente a admitir erradamente que o famoso descobridor teria estado em Portugal em i512, quando então estava nas Molucas.

Relativamente aos quatro documentos espanhóis relativos à preparação da viagem de Fernão de Magalhães há a realçar que eles são os únicos que sobreviveram de entre os que estiveram na sua nau Trinidad, nela tendo sido apreendidos pelos portugueses quando esse navio foi levada para Ternate em outubro de i522. Outros documentos que nela estiveram e vieram para Lis- 
boa perderam-se. De realçar entre aqueles documentos a carta de Carlos V em que dava ordens a Fernão de Magalhães e os demais tripulantes da armada que enviava a descobrir que fossem diretamente às Molucas. Tão importante testemunho, que só é conhecido nesta versão, atesta a insistência do monarca no objetivo principal de Fernão de Magalhães que era a sua ida a essas ilhas.

De relevar ainda a carta muito significativa que Carlos V enviou a D. Manuel I para lhe assegurar que a expedição comandada por Fernão de Magalhães não iria passar pelos seus domínios, o que atesta a evidência de que o navegador não pretendia realizar uma viagem de circum-navegação completa da Terra, pois para a fazer teria de navegar no hemisfério oriental dominado pelos portugueses.

Quanto à correspondência que foi enviada a D. Manuel I por delegados seus em Espanha, na qual se tratava de Fernão de Magalhães antes de partir para a sua viagem em I5I9, verifica-se que ela atesta o empenho português em que tal viagem não se realizasse. É particularmente notável a carta de Sebastião Álvares que revela o ambiente que havia em Sevilha antes dessa viagem e as diligências que em vão realizara junto de Fernão de Magalhães para que ele não fizesse a viagem que planeara, indicando ainda alguns dos portugueses que tencionavam embarcar na sua armada.

Em contraste com a documentação anterior à viagem de Fernão de Magalhães é também fundamental aquela que se refere a essa expedição, a qual revela a forma como foi vista a sua realização pelos portugueses.

De entre as restantes fontes históricas existentes em Portugal, são particularmente valiosas aquelas onde se registaram os testemunhos de participantes na viagem de Fernão de Magalhães, como é o caso do depoimento de Martin de Aiamonte em Malaca, que foi o primeiro a ser registado de toda a viagem, e o de León Pancaldo.

Os restantes textos aqui enunciados esclarecem ainda a forma como Fernão de Magalhães regressou a Lisboa vindo de Malaca em I5I3 e o envio da primeira carta de Francisco Serrão a Fernão de Magalhães em I5I4. Por fim, as fontes portuguesas atestam com clareza que Fernão de Magalhães era natural do Porto, como o registou entre outros o doutor João de Barros e Manuel Severim de Faria.

A superação de muitos erros que se têm cometido na abordagem da história de Fernão de Magalhães é possível alcançar através da conjugação das fontes arquivísticas existentes em Portugal com as crónicas portuguesas, de for- 
ma a esclarecer assim muitos aspetos da vida e das viagens daquele que se tornou o português mais conhecido da História e um símbolo do início do processo da mundialização, o qual está na remota origem da atual globalização que vivemos. Tal facto deve-se à circunstância de Fernão de Magalhães ter conseguido ser o primeiro homem a dar uma volta ao mundo, ainda que o tivesse feito de forma indireta em duas etapas, como já atrás referimos, além de que foi ele que esteve na origem da primeira circum-navegação da Terra realizada de seguida pela nau Victoria comandada por Juan Sebastián Elcano, quando logrou chegar a Sanlúcar de Barrameda a 6 de setembro de 1522, quase três anos depois de lá ter saído a 20 de setembro de I519.

\section{BIBLIOGRAFIA}

Academia das Ciências de Lisboa (ed.) (I892). Alguns documentos do Arquivo Nacional da Torre do Tombo acerca das navegações e conquistas portuguesas. Lisboa: Imprensa Nacional.

ÁguAs, Neves (1987). Fernão de Magalhães. A primeira viagem à volta do mundo contada pelos que nela participaram. Mem Martins: Publicações Europa-América.

Albuguerque, Afonso de (1884-1935). Cartas de Afonso de Albuquerque. Lisboa: Tip. Academia Real das Ciências de Lisboa.

BAĩ̃o, António (1905). «Fernão de Magalhães: dados inéditos para a sua biografia». Arquivo histórico português, III.

BAĩ̃o, António (1932). «A viagem de Fernão de Magalhães por uma testemunha presencial». Arquivo histórico de Portugal, 2.

Barros, Amândio (2015). O homem que navegou o mundo: em busca das origens de Magalhães. Braga: AL Publicações.

Barros, João de (1553). Segunda decada da Asia de João de Barros, dos feitos que os Portugueses fizeram no descobrimento E conquista dos mares e terras do oriente. Lisboa: Germão Galhardo.

Barros, João de (1563). Terceira decada da Asia de Ioam de Barros: Dos feitos que os Portugueses fizeram no descobrimento \& conquista dos mares $\&$ terras do Oriente. Lisboa: João de Barreira.

Castanheda, Fernão Lopes de (1552). Ho terceiro livro da Historia do descobrimento $\&$ conquista da India pelos Portugueses Feita per Fernão Lopes de Castanheda. Coimbra: João da Barreira e João Álvares.

Castro, Xavier de; Hamon, Jocelyne; Thomaz, Luís Filipe F. R. (ed.) (20ro). Le voyage de Magellan (1519-1522): la relation d'Antonio Pigafetta et autres témoignages. $2^{\mathrm{a}}$ ed. París: Chandeigne. 
Contesão, Jaime (ed.) (I956-I96i). Pauliceae lusitana monumenta historica. Lisboa: Real Gabinete Português de Leitura do Rio de Janeiro.

Denucé, Jean (I9II). Magellan: la question des Moluques et la première circumnavigation du globe. Bruselas: Hayez.

Eliot Morison, Samuel (i974). The european discovery of America: the southern voyages, a. D. I492-ı6r6. Nueva York: Oxford University Press.

Fernández de Navarrete, Martin (I825-I837). Colección de los viajes y descubrimientos que hicieron por mar los españoles desde fines del siglo XV. Madrid: Imprenta Nacional.

FonsecA, Luís Adão da; Ruiz Asencio, José Manuel (coord.) (i994). Corpus documental del tratado de Tordesillas. Valladolid: Sociedad V Centenario del Tratado de Tordesillas; Lisboa: Comissão Nacional para as Comemorações dos Descobrimentos Portugueses.

Garcia, José Manuel (2007). A viagem de Fernão de Magalhães e os portugueses. Lisboa: Presença.

Garcia, José Manuel (20I7). O terrível: a grande biografia de Afonso de Albuquerque. Lisboa: Esfera dos Livros.

Garcia, José Manuel (20I9). Fernão de Magalhães: Lisboa e o início da mundialização. Lisboa: Câmara Municipal de Lisboa (no prelo).

Gavetas (1960-I977) da Torre do Tombo, As. Lisboa: Centro de Estudos Históricos Ultramarinos.

LagoA, Visconde de (1938). Fernão de Magalhães: a sua vida e a sua viagem. Lisboa: Seara Nova.

Sá, Artur Basílio de (ed.) (I954-I988). Documentação para a História das missões do Padroado Português do Oriente: Insulíndia. Lisboa: Agência Geral do Ultramar.

Saraiva, Cardeal (I8I2-i867). Collecção de noticias para a História e Geografia das nações ultramarinas, que vivem nos dominios portuguezes, ou lhes são visinhas. Lisboa: Academia Real das Ciências.

Silva, Joaquim Candeias (1996). O fundador do «Estado Português da Índia»: D. Francisco de Almeida. Lisboa: Comissão Nacional para as Comemorações dos Descobrimentos Portugueses; Imprensa Nacional-Casa da Moeda.

Veloso, Queirós (194I). Fernão de Magalhães: a vida e a viagem. Lisboa: Ocidente.

Viterbo, Sousa (I988). Trabalhos náuticos dos Portugueses nos séculos XVI e XVII, reprodução fac-similada com introdução de José Manuel Garcia. Lisboa: Imprensa Nacional-Casa da Moeda. 